\title{
Neonectria Canker Found on Spruce and Fir in Swedish Christmas Tree Plantations
}

\begin{abstract}
Martin Pettersson and John Frampton, Department of Forestry and Environmental Resources, North Carolina State University, Raleigh 27695 USA; Jonas Rönnberg, Southern Swedish Forest Research Centre, Swedish University of Agricultural Sciences, 23053 Alnarp, Sweden; and Venche Talgø, Biotechnology and Plant Health Division, Norwegian Institute of Bioeconomy Research, 1431 Ås, Norway
\end{abstract}

Accepted for publication 1 September 2016.

Although Norway spruce (Picea abies) remains the dominant Christmas tree grown in Sweden, fir (Abies spp.) production has steadily increased since the 1980s, especially Nordmann fir ( $A$. nordmanniana). In May 2015, twenty-one Christmas tree farms in southern Sweden (Fig. 1) were surveyed to identify prominent disease and pest problems. Visual inspection found dead tops of Norway spruce on more than $50 \%$ of the farms. Often one third of the upper part of the tree was dead. Additionally, dead shoots were found on eight Nordmann and noble fir (A. procera) trees.

Samples from symptomatic trees were incubated in moist chambers and/or wood samples were plated on potato dextrose agar (PDA) after submerging the samples for $10 \mathrm{~s}$ in $70 \%$ ethanol and $90 \mathrm{~s}$ in $0.5 \% \mathrm{NaOCl}$ solution. Morphological identification of pure cultures was confirmed by sequencing the internal transcribed spacer (ITS) region of the ribosomal DNA using the primers ITS4 and ITS5. Sequences were compared with published sequences using the National Center for Biotechnology Information (NCBI) GenBank BLASTn tool; 99 to $100 \%$ identity was found for all isolates. Accession numbers were assigned using the BankIt Submission Tool (Table 1). Among the identified fungi were two Neonectria species: $N$. fuckeliana from Norway spruce and $N$. neomacrospora from Nordmann fir. This is the first report of $N$. neomacrospora in Sweden and of $N$. fuckeliana causing top dieback on young spruce.

Neonectria fuckeliana was identified from dead tops of Norway spruce at six different sites in the counties of Västra Götaland, Halland, and Skåne (Fig. 2A). Cultures were successfully isolated on PDA from wood samples taken at the margin of the necrotic zone of three diseased Norway spruce trees (Fig. 3A). Incubated wood samples from three other Norway spruce yielded characteristic, red fruiting bodies (perithecia) and mycelial cushions (sporodochia) with asexual spore mass (Figs. 2B and 2C). White spore tendrils emerged from perithecia after 3 to 5 days incubation. Asexual spores, both multiseptated (1 to 6 septa) macroconidia of the Cylindrocarpon stage and microconidia of the Acremonium stage, developed (Fig. 3B). Macroconidia measured 32.6 to 63.3 (mean 45.4 ) $\times 2.4$ to 4.3 (mean 3.0$) \mu \mathrm{m}$ $(\mathrm{n}=25)$. Neonectria neomacrospora was isolated on PDA (Fig. 3C) from Nordmann fir at three different sites, two from dead shoots of Christmas trees (Fig. 2D) in Västra Götaland County and one from an older tree in an ornamental planting in Skåne County (Table 1). The isolates were $100 \%$ identical to N. neomacrospora sequences reported to the NCBI GenBank nucleotide

Corresponding author: Martin Pettersson. Email: jmpetter@ncsu.edu.

doi:10.1094/PHP-BR-16-0017

(C) 2016 The American Phytopathological Society database. Red perithecia and sporodochia were also found on incubated Nordmann fir branches (Figs. 2E and 2F). Macroconidia (1 to 3 septa) of the Cylindrocarpon stage and microconidia of the Acremonium stage developed (Fig. 3D). Macroconidia measured 13.5 to 29.1 (mean 21.4 ) $\times 2.4$ to 4.2 (mean 3.1) $\mu \mathrm{m}$ $(\mathrm{n}=25)$. Inoculation tests were performed using map pins contaminated with mycelia inserted into stems of seedlings and the map pins were left standing in the inoculation site throughout the experimental period according to Talg $\varnothing$ and Stensvand (2013). Results verified that $N$. fuckeliana (Accession Nos. KT350496 and KT350495) and N. neomacrospora (KT350497) were patho-

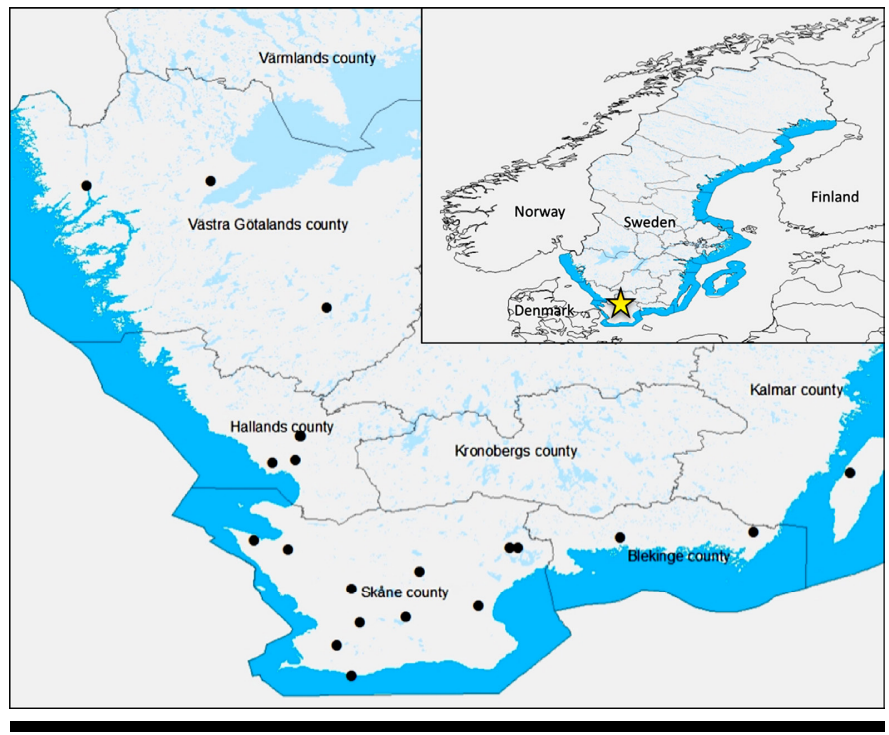

FIGURE 1

Map of southern Sweden indicating the positions of the Christmas tree fields included in a disease and pest survey in 2015.

\begin{tabular}{lllc}
\multicolumn{5}{c}{ TABLE 1 } \\
\multicolumn{4}{c}{$\begin{array}{c}\text { Neonectria spp. isolates obtained from six different } \\
\text { Christmas tree fields in a disease and pest survey of } \\
\text { 21 farms in southern Sweden in 2015. }\end{array}$} \\
Species & Location & $\begin{array}{c}\text { Isolate } \\
\text { No. }\end{array}$ & $\begin{array}{c}\text { GenBank } \\
\text { Accession No. }\end{array}$ \\
\hline N. fuckeliana & Skåne & 250469 & KT438903 \\
N. fuckeliana & Skåne & 250470 & KT350496 \\
N. fuckeliana & Skåne & 250471 & KT350495 \\
N. neomacrospora & Västra Götaland & 250472 & KT350497 \\
N. neomacrospora & Västra Götaland & 250473 & KT383060 \\
N. neomacrospora & Skåne & 250474 & KT383061 \\
\hline
\end{tabular}




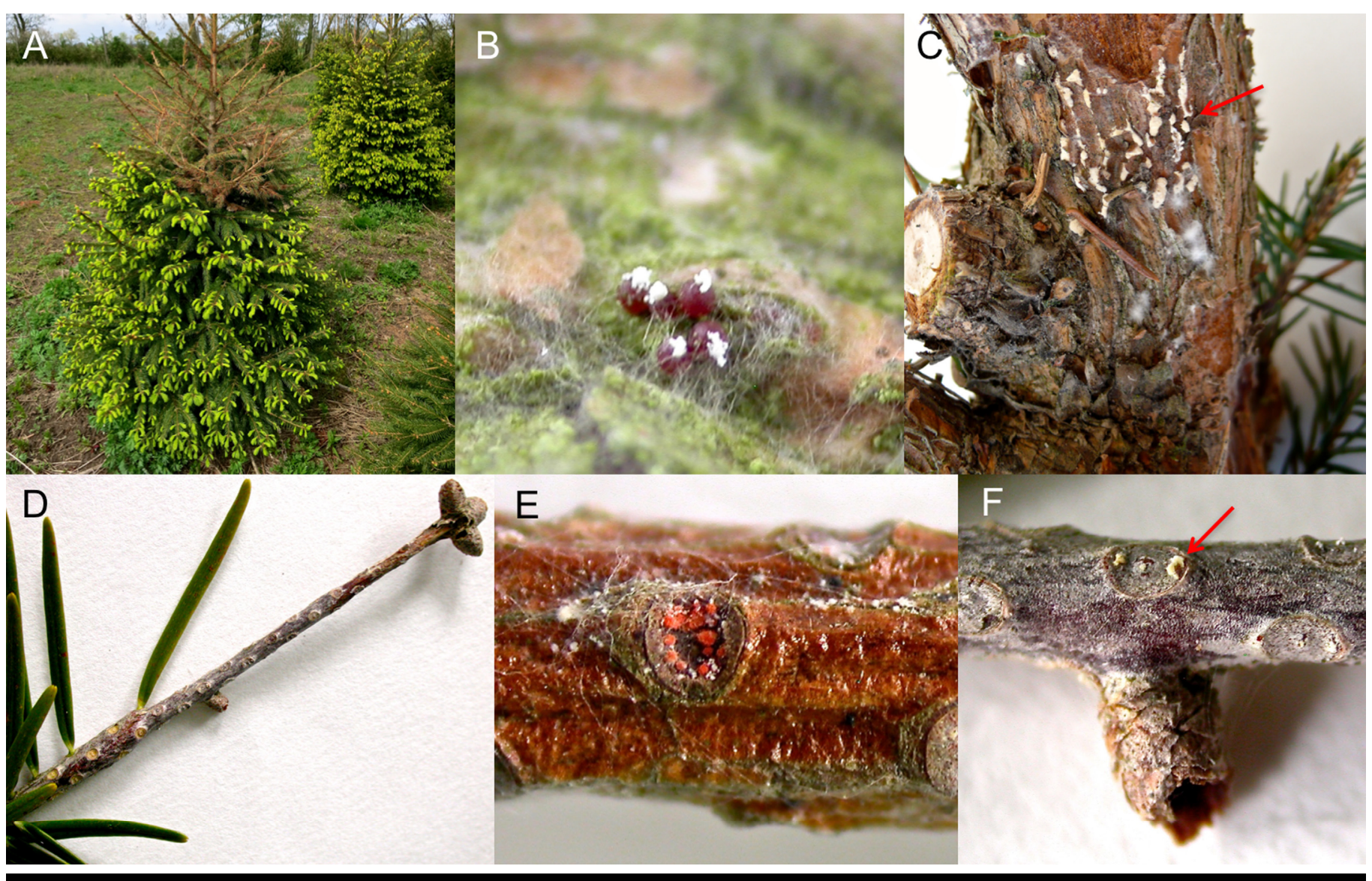

FIGURE 2

Symptoms and signs of Neonectria canker on Christmas trees in Sweden: (A) dead top, (B) perithecia with emerging ascospore tendrils, and (C) sporodochia with asexual spore mass from Neonectria fuckeliana on Norway spruce (Picea abies); and (D) a dead branch tip, (E) perithecia in a needle scar, and (F) sporodochia of N. neomacrospora on Nordmann fir (Abies nordmanniana). Photos: (A, D) Martin Pettersson and (B, C, E, F) Venche Talgø.

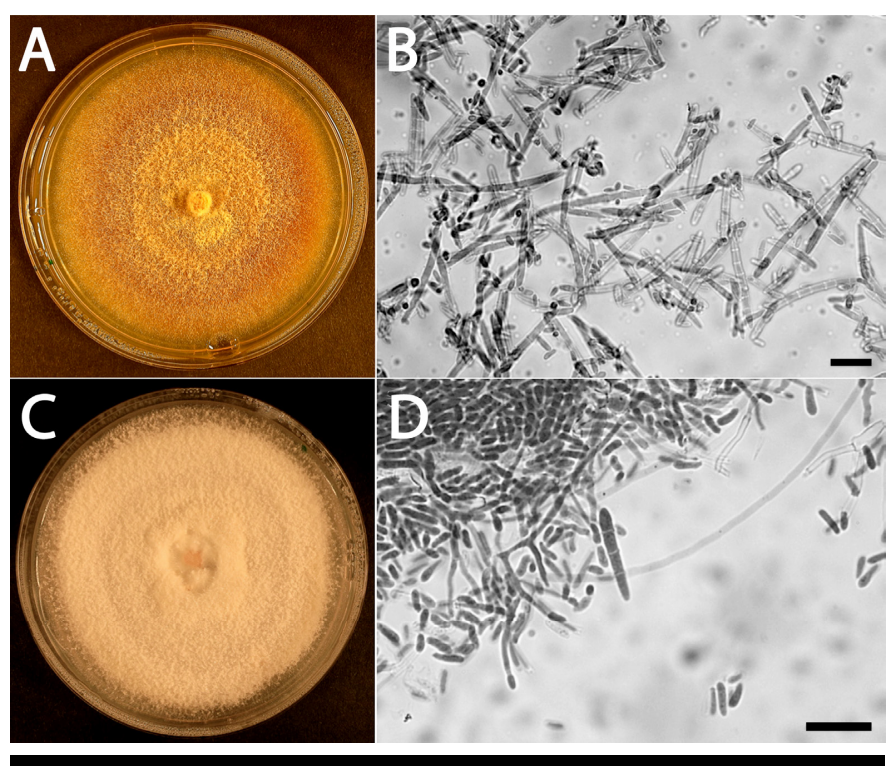

FIGURE 3

Morphological features of Neonectria spp. found on spruce and fir in Sweden: (A) yellow/orange, floccose culture on PDA, and (B) macroand microconidia of Neonectria fuckeliana; (C) whitish, floccose culture on PDA; and (D) macro- and microconidia of N. neomacrospora. Both cultures were 20 days old. Scale bar $=20 \mu \mathrm{m}$. Photos: Martin Pettersson. genic to Norway spruce and Nordmann fir, respectively. Six 2year-old and ten 5-year-old Norway spruce plants were inoculated with $N$. fuckeliana while three were kept as controls (sterile map pins inserted). For N. neomacrospora, 18 two-year-old plants were inoculated and 6 were kept as controls. The plants were exposed to outdoor conditions: -2.7 to $31^{\circ} \mathrm{C}$ (mean $12.5^{\circ} \mathrm{C}$ ), 20.6 to $100 \%$ (mean $81.7 \%$ ) $\mathrm{RH}$, in natural daylight. All inoculated plants showed canker wounds resulting in dead shoots. Both fungi were readily reisolated (fulfilling Koch's postulates) (Fig. 4) while the control plants remained healthy. Optimal temperature for both $N$. fuckeliana and $N$. neomacrospora was $20^{\circ} \mathrm{C}$ (Fig. 5).

Neonectria fuckeliana causes cankers and dieback of Monterey pine (Pinus radiata) in New Zealand (Crane et al. 2009). It also commonly occurs on Norway spruce (Picea abies) in Scandinavia, where it is regarded as a weak pathogen. However, $N$. fuckeliana was recently reported to cause severe cankers in Norway spruce forests in Finland (Lilja et al. 2012). A similar situation has been observed in Norway (Talgø et al. 2015). Neonectria neomacrospora was found on fir species in North America and Norway more than 50 years ago (Booth 1979), but no severe damage was observed until recently. Since 2008, $N$. neomacrospora has been isolated from 19 fir species in Norway, Denmark, and western United States and has caused epidemic outbreaks and mortality (Talgø and Thomsen 2015). Follow-up studies on distribution and management of both Neonectria spp. will be undertaken. In particular, $N$. fuckeliana should be followed especially closely because it affects Norway spruce, the most important forest tree in Sweden. 


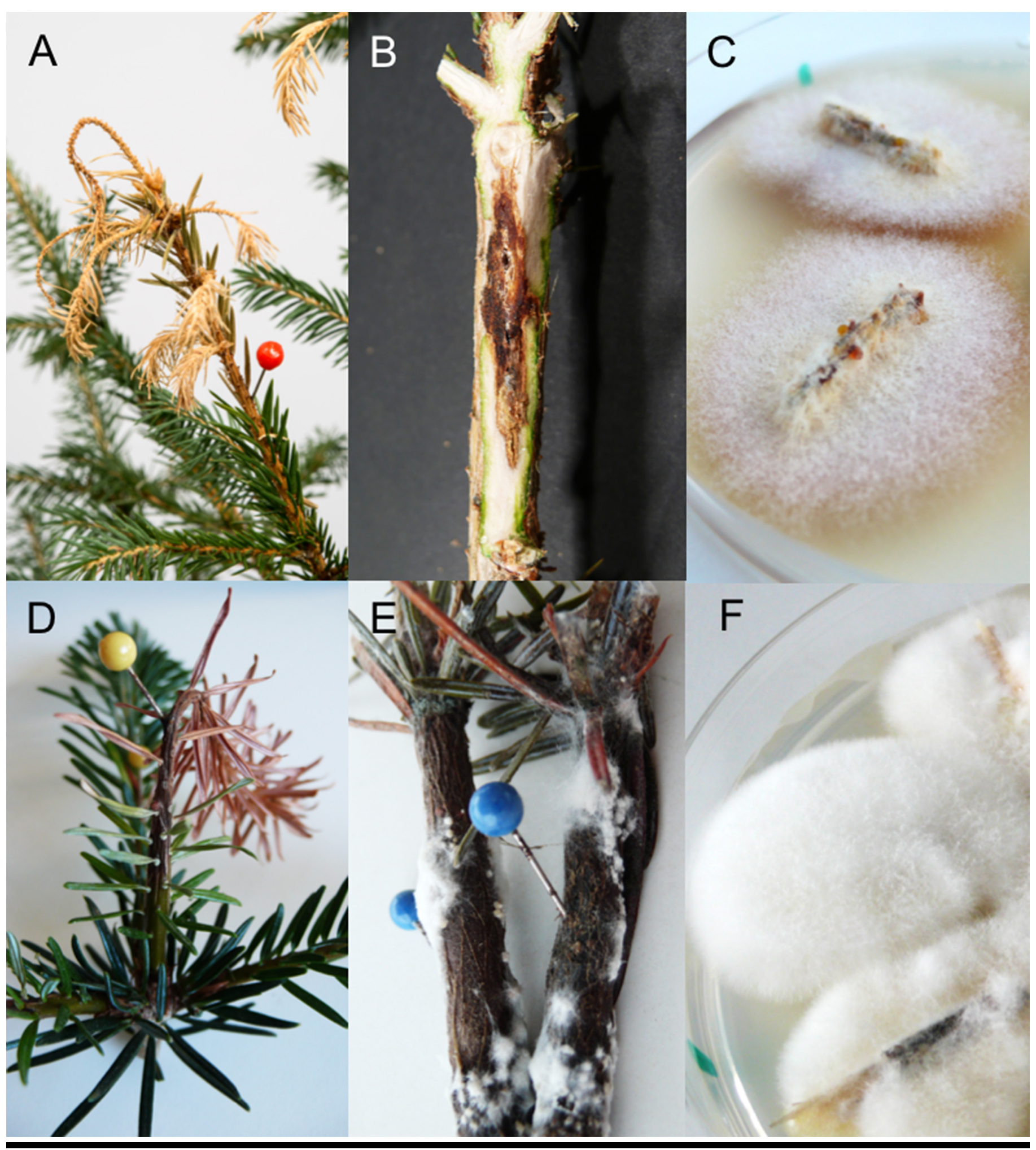

FIGURE 4

Results from inoculation tests using map pins with mycelium of Neonectria spp.: (A) dead shoot and (B) canker wound on Norway spruce (Picea abies) 144 days after inoculation with Neonectria fuckeliana; (C) re-isolation of N. fuckeliana on PDA; (D) dead shoot on Nordmann fir (Abies nordmanniana) 222 days after inoculation with N. neomacrospora; (E) incubated Nordmann fir stems displaying white mycelium of $N$. neomacrospora in the infected area; (F) reisolation of N. neomacrospora on PDA. Photos: (A) Erling Fløistad and (B, C, D, E, F) Venche Talgø. 


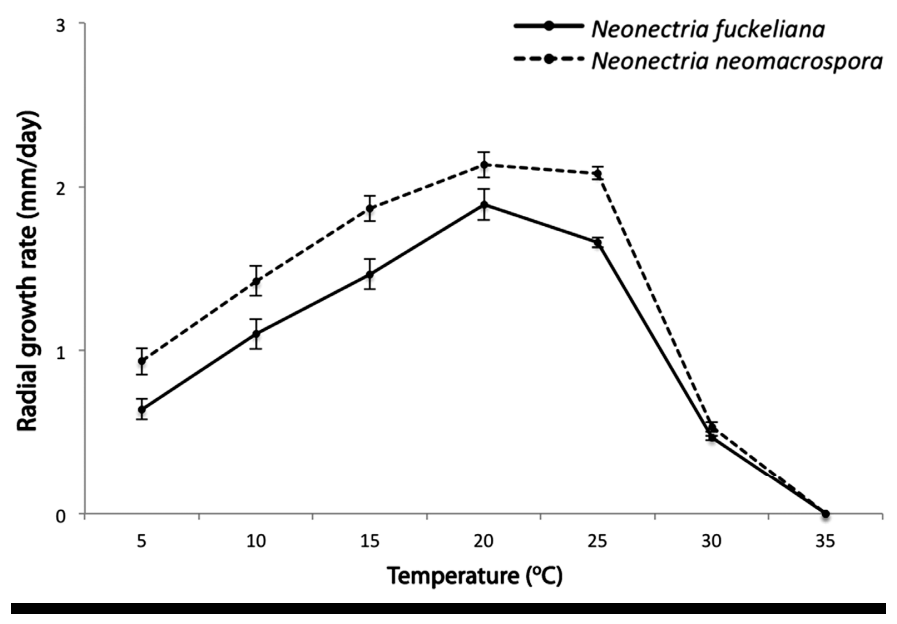

FIGURE 5

Radial growth rates in millimeters per day of Neonectria fuckeliana (GenBank Accession No. KT350495) and N. neomacrospora (KT350497) grown on PDA in darkness at 5-degree intervals from 5 to $35^{\circ} \mathrm{C}$.

\section{LITERATURE CITED}

Booth, C. 1979. Nectria macrospora. No. 623 in: Description of Pathogenic Fungi and Bacteria, CMI, Kew, Surrey, UK.

Crane, P. E., Hopkins, A. J., Dick, M. A., and Bulman, L. S. 2009. Behaviour of Neonectria fuckeliana causing a pine canker disease in New Zealand. Can. J. For. Res. 39:2119-2128.

Lilja, A., Rytkönen, A., Napola, M.-L., Napola, J., Talgø, V., Poteri, M., and Hantula, J. 2012. Neonectria sp., a new pathogen causing cankers on Norway spruce? J. Agric. Ext. Rural Dev. (JAERD) 4(9):285.

Talgø, V., Solheim, H., Børja, I., Thomsen, I. M., and Pettersson, J. M. 2015. Kreftsår på gran. Norsk Skogbruk 61(9):33. (in Norwegian)

Talg $\varnothing$, V., and Stensvand, A. 2013. A simple and effective inoculation method for Phytophthora and fungal species on woody plants. EPPO Bulletin 43:276-279.

Talgø, V., and Thomsen, I. M. 2015. Neonectria neomacrospora. Pages 38-39 in: V. Talg $\varnothing$ and I. Fløistad, eds. Skader i juletrefelt - biotiske og abiotiske årsaker. Bioforsk Fokus 10(5). (in Norwegian, English summary) 